$\mathbf{R}_{\text {EVIEW }}$

A rticle

\section{The role of veterinarians in quality meat production}

\author{
CHANDRA SHEKHAR
}

AUTHOR FOR CORRESPONDENCE :

\section{CHANDRA SHEKHAR}

Department of Veterinary Public Health and Epidemiology, College of Veterinary Science and Animal Husbandry, N.D. University of Agriculture and Technology,

Kumarganj, FAIZABAD (U.P.) INDIA

Email : cshekharvph@gmail.com

\begin{abstract}
Veterinarians in the world are closely involved with foods of animal origin. Veterinarians working in both government and in the private sector as well as veterinarians working in research facilitate the safe production of food. Veterinarians have key roles in all aspects of the control of food-borne hazards of animal origin. The traditional focus of veterinary involvement in food safety has been in meat hygiene at the level of the slaughterhouse. The education and training of veterinarians, which includes both animal health (including zoonoses) and food hygiene components, makes them uniquely equipped to play a central role in ensuring food safety, especially the safety of foods of animal origin. Veterinarians play a key role in ensuring that animals are kept under hygienic conditions and in the early detection, surveillance and treatment of animal diseases, including conditions of public health significance. Veterinarians also provide livestock producers with information, advice and training on how to avoid, eliminate or control food safety hazards (e.g., drug and pesticide residues, mycotoxins and environmental contaminants) in primary production, including through animal feed. Veterinarians have the knowledge and expertise to audit the standards of animal health, animal welfare and public health from "stable to table".
\end{abstract}

Key words : Veterinarians, Antemortem inspection, Postmortem inspection, Food safety

How to cite this paper : Shekhar, Chandra (2016). The role of veterinarians in quality meat production. Vet. Sci. Res. J., 7(2) : 122-128, DOI : 10.15740/HAS/VSRJ/7.2/122-128.

Paper History : Received : 26.08.2016; Accepted : 24.09.2016 